\title{
Mesencephalic Astrocyte-Derived Neurotrophic Factor Is Neurorestorative in Rat Model of Parkinson's Disease
}

\author{
Merja H. Voutilainen, ${ }^{1}$ Susanne Bäck, ${ }^{1}$ Eeva Pörsti, ${ }^{1}$ Liisa Toppinen, ${ }^{1}$ Lauri Lindgren, ${ }^{1}$ Päivi Lindholm, ${ }^{2}$ \\ Johan Peränen, ${ }^{2}$ Mart Saarma, ${ }^{2}$ and Raimo K. Tuominen ${ }^{1}$ \\ ${ }^{1}$ Division of Pharmacology and Toxicology, Faculty of Pharmacy, and ${ }^{2}$ Institute of Biotechnology, Viikki Biocenter, University of Helsinki, FIN-00014 \\ Helsinki, Finland
}

Neurotrophic factors are promising candidates for the treatment of Parkinson's disease (PD). Mesencephalic astrocyte-derived neurotrophic factor (MANF) belongs to a novel evolutionarily conserved family of neurotrophic factors. We examined whether MANF has neuroprotective and neurorestorative effect in an experimental model of PD in rats. We also studied the distribution and transportation of intrastriatally injected MANF in the brain and compared it with glial cell line-derived neurotrophic factor (GDNF). Unilateral lesion of nigrostriatal dopaminergic system was induced by intrastriatal injection of 6-hydroxydopamine (6-OHDA). Amphetamine-induced turning behavior was monitored up to 12 weeks after the unilateral lesion. The local diffusion at the injection site and transportation profiles of intrastriatally injected MANF and GDNF were studied by immunohistochemical detection of the unlabeled growth factors as well as by autoradiographic and gamma counting detection of ${ }^{125}$ I-labeled trophic factors. Intrastriatally injected MANF protected nigrostriatal dopaminergic nerves from 6-OHDA-induced degeneration as evaluated by counting tyrosine hydroxylase (TH)-positive cell bodies in the substantia nigra (SN) and TH-positive fibers in the striatum. More importantly, MANF also restored the function of the nigrostriatal dopaminergic system when administered either $6 \mathrm{~h}$ before or 4 weeks after 6-OHDA administration in the striatum. MANF was distributed throughout the striatum more readily than GDNF. The mechanism of MANF action differs from that of GDNF because intrastriatally injected ${ }^{125} \mathrm{I}$-MANF was transported to the frontal cortex, whereas ${ }^{125} \mathrm{I}$-GDNF was transported to the SN. Our results suggest that MANF is readily distributed throughout the striatum and has significant therapeutic potential for the treatment of PD.

\section{Introduction}

Parkinson's disease (PD) is a progressive degenerative brain disease characterized by bradykinesia, resting tremor, muscle rigidity, and postural abnormalities (Dauer and Przedborski, 2003). The movement disorder is mainly a consequence of degeneration of dopamine (DA) neurons projecting from the substantia nigra (SN) to the caudate-putamen. Current therapies of PD provide relief of motor symptoms but do not prevent disease progression (Di Stefano et al., 2008). Thus, there is a need for therapies that can slow down neurodegeneration and restore the function of neural circuits controlling movements. Many neurotrophic factors show neuroprotective properties in vitro (for review, see Bespalov and Saarma, 2007). However, only glial cell line-derived neurotrophic factor (GDNF) (Hoffer et al., 1994; Kearns and Gash, 1995; Tomac et al., 1995a; Gash et al., 1996; Zhang et al., 1997) and neurturin (NRTN) (Horger et al., 1998; Rosenblad et al., 1999; Oiwa et al., 2002) and conserved dopamine neurotro-

\footnotetext{
Received Feb. 18, 2009; revised May 29, 2009; accepted June 10, 2009.

This work was supported by the Michael J. Fox Foundation, Academy of Finland Center of Excellence and Neuroscience Programs, and the Sigrid Jusélius Foundation. M.H.V. was supported by the Finnish Cultural Foundation and the Finnish Parkinson Foundation. We thank M. Baarman, M. Lindgren, A. Niemi, M. Palviainen, K. Rautio, M. Vaha, and S. Åkerberg for excellent technical assistance.

M.H.V., P.L., J.P., M.S., and R.K.T. have submitted a patent application on the therapeutic use of MANF.

Correspondence should be addressed to Dr. Mart Saarma, Institute of Biotechnology, P.0. Box 56, Viikki Biocenter, University of Helsinki, FIN-00014 Helsinki, Finland. E-mail: mart.saarma@helsinki.fi.

DOI:10.1523/JNEUROSCI.0833-09.2009

Copyright $\odot 2009$ Society for Neuroscience $\quad$ 0270-6474/09/299651-09\$15.00/0
}

phic factor (CDNF) (Lindholm et al., 2007) can protect and repair the nigrostrial dopaminergic system in animal models of $\mathrm{PD}$ in vivo.

Despite the promising preclinical data, intracerebroventricular infusion of GDNF in parkinsonian patients resulted in no therapeutic benefit and produced serious side effects (Nutt et al., 2003). Intraputamenal infusions resulted in clear clinical improvement in two open-label studies (Gill et al., 2003; Slevin et al., 2005), but not in a randomized, double-blind clinical trial (Lang et al., 2006). NRTN protein is structurally homologous to GDNF (Kotzbauer et al., 1996). Adenoassociated virus (AAV) type 2-based vector (NRTN-AAV2) was used for the delivery of NRTN gene aiming at local production of NRTN in striatum (STR) of parkinsonian patients (Marks et al., 2008). Recently, significant improvement as compared to placebo-treated controls was observed (R. Bartus, personal communication).

The poor outcome in the clinical trials with GDNF and NRTN may result from their inappropriate concentrations at the site of neurodegeneration. Both GDNF and NRTN bind with high affinity to heparan sulfates in the extracellular matrix (ECM) that limits the volume of their distribution (Hamilton et al., 2001; Salvatore et al., 2006). Therefore, it is important to find other neurorestorative factors with low affinity to the ECM.

CDNF (Lindholm et al., 2007) and mesencephalic astrocytederived neurotrophic factor (MANF) (Petrova et al., 2003) are secreted proteins with eight cysteine residues. They form a novel, 
evolutionarily conserved neurotrophic factor family. CDNF and MANF are found in the vertebrates, whereas a single CDNF/ MANF homolog is present in the invertebrates (Lindholm et al., 2008; Palgi et al., 2009). MANF was shown to protect rat embryonic nigral dopaminergic neurons in vitro (Petrova et al., 2003). MANF protein is upregulated in cerebral ischemia in rats and is cytoprotective against endoplasmic reticulum (ER) stress in various cell lines (Apostolou et al., 2008). Keeping in mind the homology between CDNF and MANF and that MANF is expressed in the striatum (Lindholm et al., 2008), we investigated the effects of MANF in a rat experimental model of PD. Intrastriatal delivery of MANF protects and repairs nigrostriatal dopamine neurons against 6-hydroxydopamine (6-OHDA)-induced toxicity. Local diffusion of MANF in STR was better than that of GDNF. Intrastriatally injected MANF and GDNF have also different transportation profiles in the rat brain.

\section{Materials and Methods}

\section{Animals}

Adult male Wistar rats (Harlan) weighing 250-280 g at the beginning of the experiment were used. The rats were housed in groups of three to four under a $12 \mathrm{~h}$ light/dark cycle at an ambient temperature of $22^{\circ} \mathrm{C}$. Tap water and rat chow (Harlan Teklad Global Diet) were available ad libitum. The use of experimental animals was approved by the Committee for Animal Experiments of the University of Helsinki and the chief veterinarian of the County Administrative Board (permissions HY 17-03 and HY 14-06).

\section{Production and purification of human recombinant MANF}

The human MANF open reading frame (excluding the signal peptide) was cloned into a T7lac based vector containing a his-tag fusion (Peränen et al., 1996). The vector was transformed into Origami B cells (Novagen), and the protein was expressed in the presence of IPTG (isopropyl $\beta$-Dthiogalactoside) for $3 \mathrm{~h}$ at $37^{\circ} \mathrm{C}$. The cells were lysed in lysis buffer $(20 \mathrm{~mm}$ Tris $\mathrm{HCl}, \mathrm{pH} 8.0,0.5 \%$ Triton X-100, $0.4 \mathrm{~mm}$ PMSF) by sonication. Then, $\mathrm{NaCl}$ and imidazole were added to a final concentration of 0.5 and $0.02 \mathrm{M}$, respectively. After centrifugation $\left(15,000 \times g\right.$ for $15 \mathrm{~min}$ at $\left.4^{\circ} \mathrm{C}\right)$ the supernatant was passed through a $0.45 \mu \mathrm{m}$ filter. The his-MANF protein was purified by the HisTrap kit according to the manufacturer (GE Healthcare). The his-tag was cleaved from his-MANF by AcTEV (Invitrogen). The his-tag and AcTEV were removed by applying them to a HiTrap Chelating column and MANF was collected from the flowthrough. MANF was finally passed through a HiTrap Q column (GE Healthcare, Buckinghamshire, UK) to get rid of small contaminants of the AcTEV and his-tag. MANF was concentrated using an Amicon Ultra-4 filter device (Millipore), and the buffer was simultaneously changed to PBS. Aliquots of MANF were snap frozen in liquid nitrogen and stored at $-80^{\circ} \mathrm{C}$.

\section{Intrastriatal injections of neurotrophic factors and 6-OHDA}

For the neuroprotection studies, stereotaxic surgery was performed in two sessions (Kearns et al., 1997; Lindholm et al., 2007) using isoflurane anesthesia (4.5\% during induction and 3\% during maintenance). The animals were placed in a stereotaxic frame (Stoelting). The skull was exposed and burr holes were made using a high-speed dental drill. Injections were performed using a $10 \mu \mathrm{l}$ Hamilton microsyringe at a rate of 1 $\mu \mathrm{l} / \mathrm{min}$. At the completion of each injection, the needle was kept in place for $2 \mathrm{~min}$ to minimize backflow of the solution. All control animals were administrated $4 \mu \mathrm{l}$ of PBS or $10 \mathrm{~mm}$ citric acid in the left striatum using coordinates relative to the bregma and dura [anterior/posterior $(\mathrm{A} / \mathrm{P})$, + 1.0; lateral/medial (L/M), +2.7; dorsal/ventral (D/V), -5] according to the atlas of Paxinos and Watson (1997). Trophic factor-treated animals received either 3,10 , or $30 \mu \mathrm{g}$ of human MANF or $10 \mu \mathrm{g}$ of recombinant human GDNF (PeproTech) in a $4 \mu \mathrm{l}$ buffer delivered to the striatum. In the second surgery, $6 \mathrm{~h}$ later, all animals were given $8 \mu \mathrm{g}$ in 4 $\mu \mathrm{l}$ of 6-OHDA (Sigma-Aldrich; calculated as free base, dissolved in icecold saline with $0.02 \%$ ascorbic acid) in the left striatum. Before 6-OHDA injections, desipramine (Sigma-Aldrich; $15 \mathrm{mg} / \mathrm{kg}$, i.p.; $1 \mathrm{ml} / \mathrm{kg}$ ) was administered to prevent the uptake of 6-hydroxydopamine into noradrenergic nerve endings and thus protect these nerve terminals from destruction. In the neurorestoration studies, the rats received a unilateral injection of $20 \mu \mathrm{g} / 4 \mu \mathrm{l}$ of 6-OHDA. Four weeks later, the rats were given an intrastriatal injection of MANF (10 $\mu \mathrm{g}$ in $4 \mu \mathrm{l}$ of PBS), GDNF (10 $\mu \mathrm{g}$ in $4 \mu \mathrm{l}$ of $10 \mathrm{~mm}$ citric acid), or vehicle. For the diffusion study, $10 \mu \mathrm{g}$ of protein (MANF or GDNF), diluted in $4 \mu \mathrm{l}$ of PBS, was injected unilaterally into the rat striatum according to the same brain coordinates as mentioned above.

\section{Behavioral analysis}

In the neuroprotection studies, behavioral tests were performed 2 and 4 weeks after lesion, and in the neurorestoration studies, behavioral tests were done 1 week before (3 weeks after 6-OHDA injection) and 2, 4, 6, and 8 weeks after lesion as described previously (Ungerstedt and Arbuthnott, 1970; Lindholm et al., 2007). Drug-induced rotational activity of the rats was monitored in automatic rotometer bowls [Colbourn Instruments (neuroprotection studies); MED Associates (neurorestoration studies)]. After a habituation period of $30 \mathrm{~min}$, a single dose of D-amphetamine (University Pharmacy, Helsinki, Finland; $2.5 \mathrm{mg} / \mathrm{kg}$ ) was injected intraperitoneally. The number of full $\left(360^{\circ}\right)$ clockwise and counterclockwise turns was recorded for a period of $2 \mathrm{~h}$. Net ipsilateral turns to the lesion were calculated by subtracting the turns to the left from the turns to the right.

\section{Histology}

Perfusion and tissue processing. At 1 or $3 \mathrm{~d}$ after protein injections (in the studies of protein diffusion) or immediately after neuroprotection or neurorestoration studies, the rats were anesthetized with an overdose of sodium pentobarbital (90 mg/kg, i.p.; Orion Pharma) and perfused intracardially with PBS followed by $4 \%$ paraformaldehyde in a $0.1 \mathrm{M}$ sodium phosphate buffer, $\mathrm{pH}$ 7.4. The brains were removed, postfixed for $4 \mathrm{~h}$, and stored in sodium phosphate buffer containing $20 \%$ sucrose at $4^{\circ} \mathrm{C}$. Serial coronal frozen sections of $40 \mu \mathrm{m}$ depth were cut on a sliding microtome.

Tyrosine hydroxylase immunohistochemistry. Six sets of sections were collected in a cryoprotectant solution ( $0.5 \mathrm{~m}$ phosphate buffer, $\mathrm{pH} 7.4$, $30 \%$ glycerol, and $30 \%$ ethylene glycol) and stored at $-20^{\circ} \mathrm{C}$ until immunohistochemical processing. Free-floating sections were processed for tyrosine hydroxylase (TH) immunohistochemistry. After three rinses in PBS, endogenous peroxidase activity was quenched for $5 \mathrm{~min}$ in $3 \%$ $\mathrm{H}_{2} \mathrm{O}_{2} / 10 \%$ methanol/PBS. After three rinses in PBS, the sections were preincubated with normal horse serum $/ 0.3 \%$ Triton X-100 in PBS to block nonspecific staining. Thereafter, sections were incubated overnight at room temperature with a 1:2000 dilution of biotinylated mouseanti-TH (Millipore Bioscience Research Reagents). This was followed by incubation with a 1:200 dilution of biotinylated horse-anti-mouse (Vector Laboratories; BA2001) and by incubation with the avidin-biotin peroxidase complex using the Elite ABC Vectastain kit (Vector Laboratories). The reactions were visualized using 3,3'-diaminobenzidine $(\mathrm{DAB})$ as a chromogen.

\section{Antibody production and specificity}

MANF antibodies were produced as described previously (Lindholm et al., 2008). Specificity of affinity-purified MANF antibodies was evaluated in Western blotting and immunohistochemistry by preincubating the affinity-purified antibody with MANF or CDNF protein as described previously (Lindholm et al., 2008).

\section{MANF and GDNF immunohistochemistry}

Forty-micrometer-thick cryosections were cut throughout the brain and stained with anti-MANF (1:100-1:300) or anti-GDNF (1:3000; R\&D Systems) antibodies using Vectastain Elite ABC kit and DAB.

\section{Morphological analysis}

SN cell counts. The optical fractionator method was used to estimate the number of TH-positive cells in the substantia nigra pars compacta (SNpc) (West et al., 1991). The entire SNpc was analyzed with the Stereo Investigator platform (MicroBrightField) attached to an Olympus BX51 microscope. From each animal, three sections from the central portion of 
the $\mathrm{SNpc}$, in which the medial terminal nucleus was present (level A/P -5.3), were selected for quantitative analysis as described previously (Lindholm et al., 2007). Each reference space was outlined at low power $(4 \times)$, and cells were counted using a high-magnification $(60 \times$, oilimmersion) objective. Cell numbers were expressed as the mean number per section. Cells were counted using the optical fractionator method in combination with the dissector principle and unbiased counting rules.

Striatal fiber density measurements. The ODs of the TH-positive fibers in the striatum were determined from three coronal striatal sections from each rat. Every sixth section between AP +1.6 and AP +0.20 was cut on a cryomicrotome (Leica Instruments) and processed for TH immunohistochemistry. Digitized images from TH-stained striata were taken with an Optronics digital camera and a constant illumination table, and fiber densities were measured using Image-Pro Plus software (version 3.0.1; Media Cybernetics). The OD analysis was performed under blinded conditions on coded slides. The data are presented as percentage of the intact side that was defined as $100 \%$.

Evaluation of protein diffusion. The area of MANF and GDNF distribution in the striatum was determined by measuring the area of immunopositive staining in square millimeters in every sixth brain section. The total protein diffusion volume was estimated with the Cavalier Estimator function of the Stereo Investigator platform using a grid spacing of $500 \mu \mathrm{m}$.

Preparation and use of ${ }^{125}$ I-labeled neurotrophic factors

GDNF $(1.5 \mu \mathrm{g})$ and MANF $(1.0 \mu \mathrm{g})$ were iodinated with ${ }^{125} \mathrm{I}-\mathrm{Na}$ using the lactoperoxidase method. The neurotrophic factor in question was dissolved in $30 \mu \mathrm{l}$ of $0.25 \mathrm{M}$ phosphate buffer, $\mathrm{pH} 7.5$, and mixed with ${ }^{125} \mathrm{I}-\mathrm{Na}(1 \mathrm{mCi}=37 \mathrm{mBq}$; GE Healthcare). The reaction was started by adding lactoperoxidase $10 \mu \mathrm{l}$ of $50 \mu \mathrm{g} / \mathrm{ml}$ and $0.05 \% \mathrm{H}_{2} \mathrm{O}_{2}$. The mixture was incubated at room temperature for $20 \mathrm{~min}$ and the reaction was stopped by adding $3 \mathrm{vol}$ of $0.1 \mathrm{M}$ phosphate buffer, $\mathrm{pH} 7.5$, containing $0.1 \mathrm{M} \mathrm{NaI}, 0.42 \mathrm{M} \mathrm{NaCl}$, and $25 \mu \mathrm{l}$ of $2.5 \%$ BSA. Free iodine and iodinated growth factor were separated by Sephadex G-25 columns (PD10; GE Healthcare). For column equilibrium and elution, $0.1 \mathrm{M}$ phosphate buffer, $\mathrm{pH} 7.5$, with $1 \%$ BSA was used. The iodinated growth factors were concentrated by using YM-10 Centricon columns (Millipore). The specific activity of ${ }^{125}$ I-labeled GDNF and MANF was $>10^{8}$ $\mathrm{cpm} / \mu \mathrm{g}$ protein.

Intrastriatal injections of ${ }^{125}$ I-neurotrophic factors. Six microliters of radiolabeled protein $(5-10 \mathrm{ng})$ plus vehicle or radiolabeled protein plus cold competitor was injected directly into the striatum using the same stereotaxic coordinates as in the neuroprotection studies. Transcardial perfusion on the rats was performed under deep anesthesia $24 \mathrm{~h}$ later. Portions of the central nervous tissue were used for gamma counting, and the remainder was sectioned for autoradiography.

Autoradiographic analysis of the distribution of ${ }^{125} I$-neurotrophic factors. Rats receiving intrastriatal injection of ${ }^{125} \mathrm{I}-\mathrm{MANF}$ (5-10 ng) or ${ }^{125} \mathrm{I}-\mathrm{GDNF}(5-10 \mathrm{ng})$ were perfused for $24 \mathrm{~h}$ after stereotaxic injections. Coronal paraffin sections ( $7 \mu \mathrm{m}$ thick) were juxtaposed against autography film (Kodak Biomax MS) for 4 weeks.

Emulsion autoradiography. Coronal paraffin sections of striatum, frontal cortex, and substantia nigra were dipped in emulsion (Kodak) and exposed for 8 weeks. Slides were developed and counterstained with hematoxylin.

Quantification of ${ }^{125}$ I-neurotrophic factors in CNS tissues after intrastriatal injections. The amount of intrastriatally administered neurotrophic factor in different brain structures was determined after perfusions. The brain was removed from the skull and the hippocampus, substantia nigra, striatum, and cortex were dissected out, and the wet tissue was weighed. Results are expressed as counts per minute per milligram of wet weight.

\section{Statistical analysis}

Results were analyzed using one-way ANOVA followed by Tukey-Kramer's post hoc test. A one-way ANOVA for repeated measures followed by Tukey-Kramer's post hoc test was used to analyze the results from behavior studies (see Fig. 1c) and from diffusion profile studies (see Fig. $5 c$ ). Student's $t$ test was used to statistically analyze total protein diffusion a

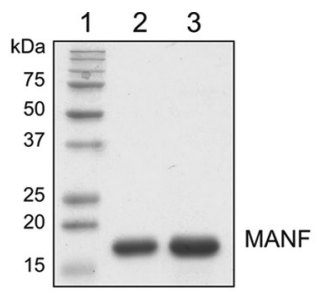

b
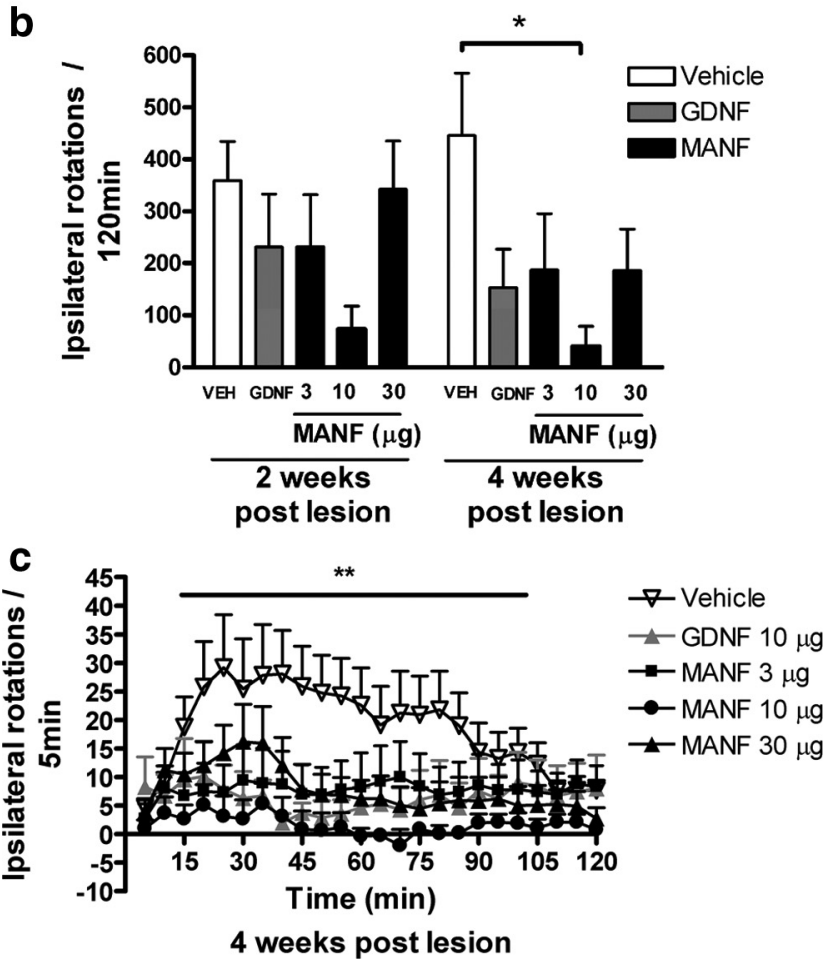

Figure 1. $\boldsymbol{a}-\boldsymbol{c}$, MANF protects against 6-OHDA induced toxicity in rats in vivo. $\boldsymbol{a}$, Purified MANF. SDS-PAGE gel stained with Coomassie brilliant blue is shown. Lane 1, Molecular weight markers; lane $2,5 \mu \mathrm{g}$ of purified MANF; lane $3 ; 10 \mu \mathrm{g}$ of purified MANF. $\boldsymbol{b}, \boldsymbol{c}$, Effect of intrastriatal injection of vehicle, MANF $(3,10$, or $30 \mu \mathrm{g})$, or GDNF $(10 \mu \mathrm{g})$ on amphetamine-induced rotation. Rats received vehicle, MANF, or GDNF in the striatum $6 \mathrm{~h}$ before a lesion was induced by intrastriatal 6-0HDA ( $8 \mu \mathrm{g}$ ). Amphetamine-induced behavior was measured for $2 \mathrm{~h}$ at 2 and 4 weeks after lesion. $\boldsymbol{b}$, Cumulative amphetamine-induced rotations. $\boldsymbol{c}$, Amphetamine-induced rotations expressed as ipsilateral rotations per $5 \mathrm{~min}$ in different treatment groups at 4 weeks after lesion. $\boldsymbol{b}, \boldsymbol{c}$, Means \pm SEM are shown; $n=7-13$ in each group. Tukey-Kramer's post hoc analysis after one-way ANOVA, ${ }^{*} p<0.05,{ }^{* *} p<0.01$ versus the corresponding control.

volume. Results are expressed as mean \pm SEM and considered significant at $p<0.05$.

\section{Results}

\section{MANF protects DA neurons against the toxic effects of 6-OHDA in vivo}

We used human recombinant MANF protein that was $>95 \%$ pure as assessed by SDS-PAGE analysis (Fig. 1a). The effect of graded doses of MANF was compared with that of GDNF in an experimental model of Parkinson's disease, as described in detail previously (Lindholm et al., 2007). A single injection of MANF (3, 10, or $30 \mu \mathrm{g} ; n=10, n=9$, and $n=11$, respectively), GDNF $(10 \mu \mathrm{g} ; n=7)$ or vehicle $(n=13)$ was given $6 \mathrm{~h}$ before neurotoxin (6-OHDA; $8 \mu \mathrm{g}$ ) unilaterally into the striatum. Amphetamine $(2.5 \mathrm{mg} / \mathrm{kg}$, i.p.) induced a strong ipsilateral turning behavior in vehicle-pretreated control rats both at 2 and 4 weeks after lesion indicating destruction of dopamine nerves in the lesioned side of the brain (Fig. 1b). MANF prevented 6-OHDA-induced degeneration of dopaminergic nerves. However, there were no statisti- 
cal differences at 2 weeks after lesion between MANF- or GDNF-treated groups and the control group. The maximum protective effect was observed with MANF dose of $10 \mu \mathrm{g}$ at 4 weeks after lesion $(p<0.05)$ (Fig. $1 b)$, and the effect was less prominent at MANF concentrations of 3 and $30 \mu \mathrm{g}$ and with GDNF (10 $\mu \mathrm{g})$. All concentrations of MANF and the positive control GDNF $(10 \mu \mathrm{g})$ significantly differed from the vehicle control at 4 weeks after lesion $(p<0.01)$ (Fig. 1c). At $10 \mu \mathrm{g} /$ striatum, MANF protected the motor function of 6-OHDA-lesioned rats more efficiently than GDNF. To verify the extent of lesion in the neuroprotection study, morphological analysis of nigral sections stained with $\mathrm{TH}$ antibody were performed 4 weeks after the lesion. Intrastriatal injection of 6-OHDA $(8 \mu \mathrm{g} /$ rat, unilaterally; $n=9$ ) resulted in $\sim 34 \%$ reduction in the number of $\mathrm{TH}$-positive neurons in SNpc compared with the intact side (Fig. 2a). Pretreatment with either MANF $(10 \mu \mathrm{g} ; n=10)$ or GDNF $(10$ $\mu \mathrm{g} ; n=8)$ significantly protected $\mathrm{TH}-$ positive cell bodies (14 and 12\% loss of TH-positive cells, respectively; $p<0.01$ ) (Fig. $2 a-e$ ) against the 6-OHDA-induced degeneration. Also at $3 \mu \mathrm{g}(n=10)$ and 30 $\mu \mathrm{g}(n=11)$, MANF protected THpositive cells, but less efficiently than at 10 $\mu \mathrm{g}$ (data not shown). The lesion caused by intrastriatal 6-OHDA was further assessed by measuring the OD of TH-positive fibers in the striatum. In these analyses, a similar trend was seen as in the $\mathrm{SN}$ cell counts. MANF at $10 \mu \mathrm{g}$ was the most effective dose tested in protecting $\mathrm{TH}$ positive fibers (26\% loss in OD) (Fig. $2 f$ ), but this dose did not statistically differ from vehicle treatment (36\% loss in OD). Neither MANF ( 3 and $30 \mu \mathrm{g}$ )- nor GDNF $(10 \mu \mathrm{g})$-treated groups showed any differences compared with the vehicle treated control-group (32, 37, or 32\% loss in OD, respectively) (Fig. $2 f-j$ ).

Behavioral measurements at 2 and 4 weeks after lesion correlated well in linear regression analysis (Fig. $3 a$, Table 1 ). This good correlation represents the changes seen in the behavior of control animals (who rotated more at 4 weeks after lesion than at 2 weeks after lesion) and in the animals treated with MANF or GDNF (who rotated less at 4 weeks after lesion than at 2 weeks after lesion). Linear regression analysis was also used to define the correlation between morphological and behavioral measurements. As expected, behavioral studies examined at 2 weeks after lesion did not significantly correlate with morphological measures measured at 4 weeks $(r<0.30$ for TH-positive cell numbers in $\mathrm{SN} ; r=0.41$ for striatal TH-positive optical fiber density) (Table 1). This low correlation is in agreement with the fact that administration of 6-OHDA into the striatum induces an acute terminal axotomy, followed by a protracted loss of the cell bodies
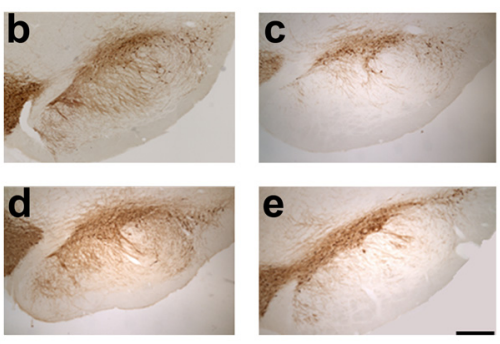

4 weeks post lesion
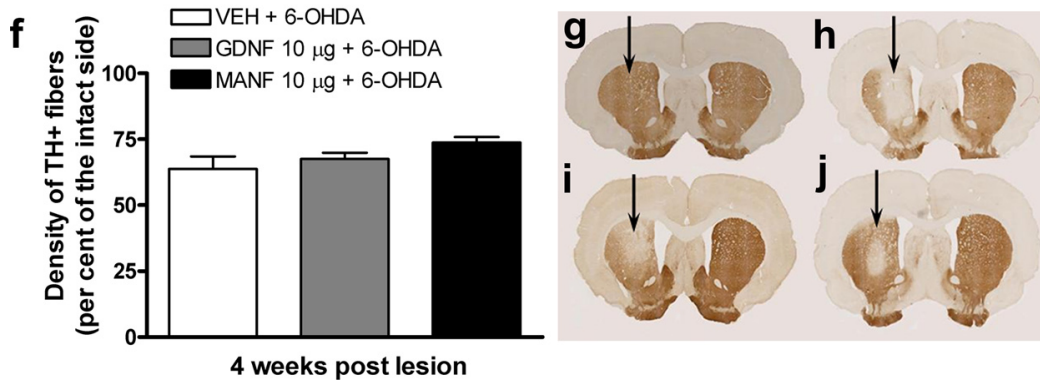

Figure 2. MANF protects TH-positive cell bodies in the substantia nigra and TH-immunoreactive fibers in the striatum from 6-OHDA. $\boldsymbol{a}$, TH-positive cell bodies in the SN analyzed at 4 weeks after lesion. In the vehicle-treated rat, intrastriatal 6-OHDA caused loss of $\sim 34 \%$ of the TH-positive cell bodies in the SN compared with the intact side. The protective effect of MANF was significant at the dose of $10 \mu \mathrm{g} \cdot \boldsymbol{b}-\boldsymbol{e}$, Photomicrographs of sections from the midbrain showing TH-immunohistochemical staining of the SN. $\boldsymbol{b}-\boldsymbol{e}$, TH-positive cells in the SNpc of an intact rat (b) or of a 6-0HDA-lesioned rat pretreated with either vehicle (c), GDNF (10 $\mu \mathrm{g})$ $(\boldsymbol{d})$, or MANF $(10 \mu \mathrm{g})(\boldsymbol{e})$. $\boldsymbol{f}$, Density of TH-positive fibers in the striatum. Optical density of striatal sections was measured at three (he intact side) in the vehicle-treated rats. MANF protected TH-positive fibers in the striatum. The GDNF-treated group did not differ from the vehicle group. $\boldsymbol{g}, \boldsymbol{h}$, Photomicrographs of striatal TH-positive fibers in an intact rat $(\boldsymbol{g})$ or pretreated either with vehicle $(\boldsymbol{h}), \mathrm{GDNF}(10 \mu \mathrm{g})$ (i) or MANF (10 $\mu \mathrm{g})(\boldsymbol{j})$. Scale bar: $\boldsymbol{b}-\boldsymbol{e}, 270 \mu \mathrm{m} . \boldsymbol{a}, \boldsymbol{f}$, Means \pm SEM are shown; $n=8-13$ in each group. Tukey-Kramer's post hoc analysis after one-way ANOVA, ${ }^{* *} p<0.01$ versus the corresponding control.
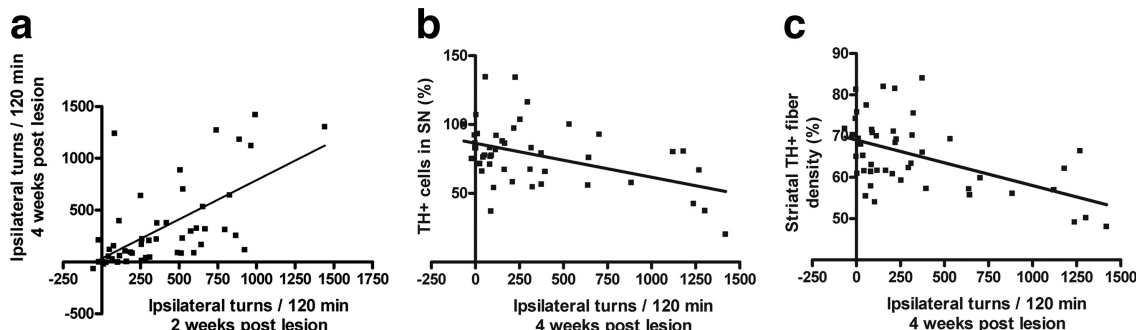

Figure 3. Relationships between behavioral and morphological measures. $\boldsymbol{a}-\boldsymbol{c}$, Correlation between amphetamine-induced rotation and $\mathrm{TH}$ immunoreactivity in brain, assessed by simple linear regression analysis. For each experimental group, the mean number of ipsilateral turns of each rat at 2 weeks after lesion is plotted against the mean number of ipsilateral turns at 4 weeks afte esion ( $\boldsymbol{a}$ ). The mean number of ipsilateral turns at 4 weeks after lesion was plotted against the mean number of TH-positive cells in the SN (expressed as percentage of the contralateral intact side) $(\boldsymbol{b})$ or against the mean striatal TH-positive fiber density (expressed as the mean of the intact side) $(\boldsymbol{c})$.

within the SN that starts $\sim 1$ week after and progresses for several weeks after an insult (Sauer and Oertel, 1994). Amphetamineinduced rotation measured at 4 weeks after lesion correlated better with TH-positive cell counts $(r=0.39)$ and TH-positive fiber density $(r=0.52)$ (Fig. 3b,c, Table 1$)$. There was also a fair correlation between $\mathrm{TH}+$ cell counts and optical density of $\mathrm{TH}-$ positive fibers (Table 1).

\section{MANF has neurorestorative effects in an experimental PD model}

Neurorestorative activity of MANF was investigated as described previously (Lindholm et al., 2007). Animals were first injected with 6-OHDA (20 $\mu \mathrm{g}$ in $4 \mu \mathrm{l}$ ) and 4 weeks later with MANF (10 
Table 1. Correlation between behavioral and morphological measures assessed by simple linear regression analysis

\begin{tabular}{|c|c|c|c|}
\hline & Amphetamine-induced rotation 4 weeks after lesion & TH-positive cell no. in SN & TH-positive fiber density in STR \\
\hline Amphetamine-induced rotation 2 weeks after lesion & $r=0.56, p<0.0001$ & $r=0.28, p<0.0492$ & $r=0.41, p<0.0020$ \\
\hline Amphetamine-induced rotation 4 weeks after lesion & & $r=0.39, p<0.0047$ & $r=0.52, p<0.0001$ \\
\hline TH-positive cell no. in SN & & & $r=0.40, p<0.0048$ \\
\hline
\end{tabular}

$\mu \mathrm{g} ; n=9)$, GDNF $(10 \mu \mathrm{g} ; n=6)$, or vehicle (controls; $n=10)$. Striatal injection of MANF and GDNF reduced amphetamineinduced ipsilateral rotational behavior compared with the control group with maximum effect measured at 12 weeks after lesion (Fig. 4a). However, the difference between treatment groups was not statistically significant. Nevertheless, when the cumulative rotations at 3, 6, 8, 10, and 12 weeks after lesion were summed, there were differences between MANF- and vehicletreated group $(p<0.001)$ and between GDNF- and vehicletreated group $(p<0.01)$ (Fig. $4 b)$. The number of TH-positive cells in the substantia nigra (measured as a percentage from the cell count of intact side) was higher in the 6-OHDA-lesioned rats treated with GDNF (59\%; $n=5)$ and in the rats treated with MANF $(59 \% ; n=6)$ than in the rats treated with vehicle only (control group; 47\%; $n=6$ ) (Fig. $4 c$ ).

\section{MANF and GDNF have differences in diffusion and} transportation profiles after intrastriatal injection Immunohistochemical staining of MANF or GDNF was performed 24 and $72 \mathrm{~h}$ after injection of the neurotrophic factors ( 10 $\mu \mathrm{g}$ in $4 \mu \mathrm{l}$ for each factor) into the striatum (Fig. $5 a, b)$. After $24 \mathrm{~h}$, the MANF protein was distributed throughout the striatum and the frontal cortex (Fig. 5a). The volume of distribution of MANF $(n=6)$ in the striatum was significantly larger than that of GDNF $(n=6)\left(49.52 \pm 3.24\right.$ vs $30.06 \pm 5.76 \mathrm{~mm}^{3}$, respectively; ${ }^{\star} p<$ 0.05 , Student's $t$ test), and the diffusion profile of MANF (Fig. $5 c$ ) correlated well with those from transport studies performed using ${ }^{125}$ I-labeled MANF protein. After $72 \mathrm{~h}$, the MANF protein was distributed to most of the ipsilateral striatum and cortex, but the staining intensity was lower than after $24 \mathrm{~h}$ (data not shown). Injection of GDNF was detected throughout the striatum $24 \mathrm{~h}$ after injection. No signal was detected in the cortical section (Fig. $5 b)$. GDNF immunoreactivity was still present in the striatum after $72 \mathrm{~h}$ (data not shown), although the staining intensity was lower than at $24 \mathrm{~h}$.

Iodinated trophic factors $\left({ }^{125} \mathrm{I}-\mathrm{MANF}\right.$ and $\left.{ }^{125} \mathrm{I}-\mathrm{GDNF}\right)$ were injected into the left striatum to coordinates $(\mathrm{A} / \mathrm{P},+1 ; \mathrm{L} / \mathrm{M}$, $+2.7 ; \mathrm{D} / \mathrm{V},-4)$ according to the rat brain atlas (Paxinos and Watson, 1997). Transport of the proteins was assessed $24 \mathrm{~h}$ after the injections based on autoradiography and radioactivity (counting with gamma spectrometer) detection of ${ }^{125} \mathrm{I}$-labeled trophic factors in brain sections. After injection of ${ }^{125} \mathrm{I}-\mathrm{MANF}$, the film autoradiography revealed radioactive signal in the ipsilateral striatum and in the cortex but not in the substantia nigra (Fig. 6a). After injection of ${ }^{125} \mathrm{I}-\mathrm{GDNF}$, radioactive signal was detected ipsilaterally in cortical (olfactory bulb) and striatal sections, as well as in the $\mathrm{SN}$ section (Fig. 6a).

Some of the brain sections were processed for emulsion autoradiography. After intrastriatal injection of ${ }^{125} \mathrm{I}-\mathrm{MANF}$, silver grains indicating radioactive signal were found near the injection site but not in the SN. After intrastriatal injection of ${ }^{125} \mathrm{I}-\mathrm{GDNF}$ (positive control), a strong signal was detected in the ipsilateral striatum and in the ipsilateral SN demonstrating transport of GDNF from the striatum into SN (data not shown). These data are in agreement with previous data that suggested that GDNF is a

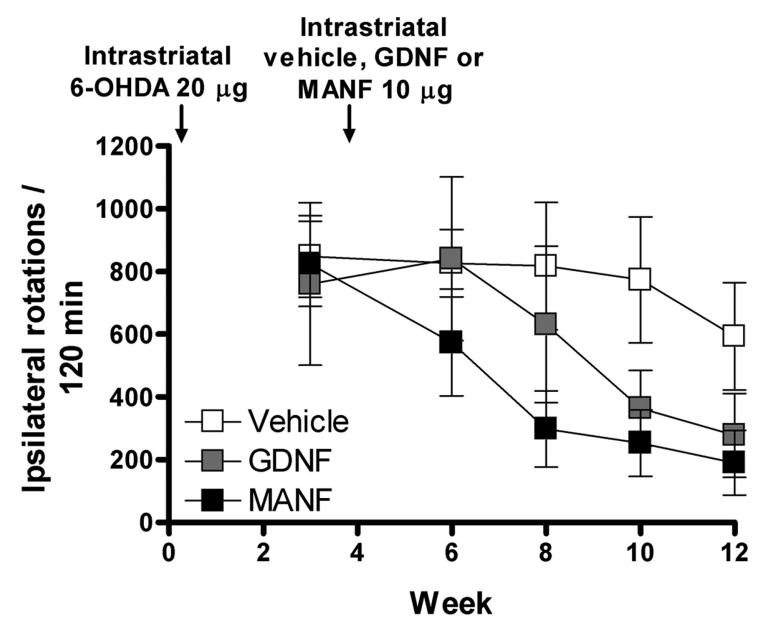

b

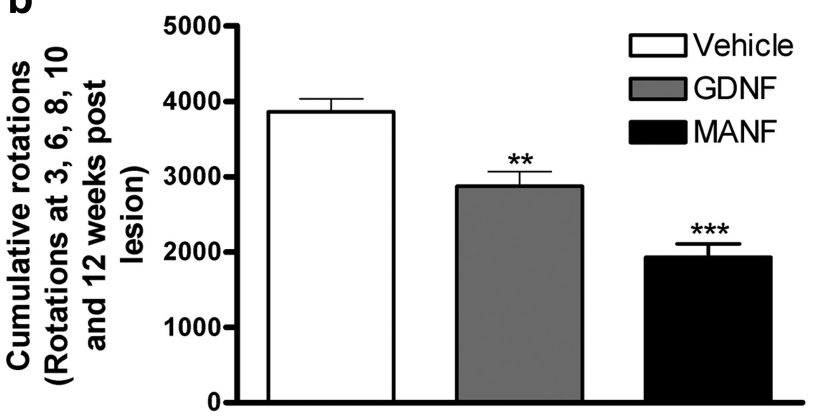

C

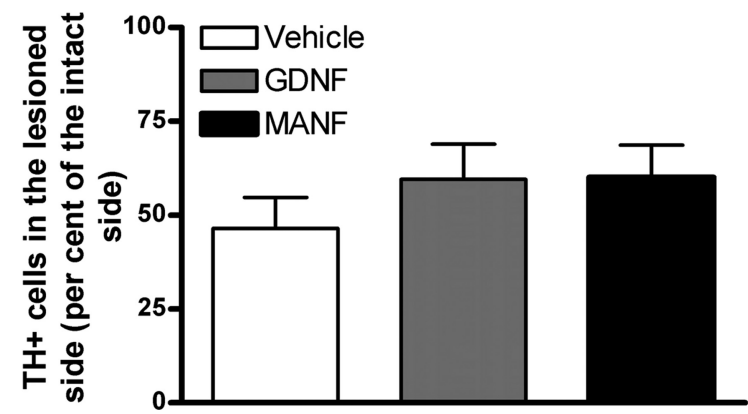

Figure 4. Neurorestorative effects of MANF. Rats were administered 6-OHDA (20 $\mu \mathrm{g})$ unilaterally in the striatum. Four weeks later, the rats received a single injection of either vehicle, $\operatorname{GDNF}(10 \mu \mathrm{g})$, or MANF $(10 \mu \mathrm{g})$. The rotational behavior was measured 1 week before and 2, 4, 6 , and 8 weeks after the injection of the growth factors. $a$, Cumulative amphetamine-induced ipsilateral rotations. Means \pm SEM are show; $n=6-10$ in each group. $\boldsymbol{b}$, Combined cumulative amphetamine-induced ipsilateral rotations measured at $3,6,8,10$, and 12 weeks after lesion. c, Number of TH-positive cells in the SNpc. Means \pm SEM are shown; $n=6-9$ in each group. Tukey-Kramer's post hoc analysis after one-way ANOVA, ${ }^{* * *} p<0.001,{ }^{* *} p<0.01$ versus the corresponding control.

retrogradely transported to the $\mathrm{SN}$ after intrastriatal injection (Tomac et al., 1995b; Lapchak et al., 1997).

To verify the results from the autoradiography experiments, we counted the radioactivity in brain samples that were removed immediately after the killing of rats. After intrastriatal injection of 
${ }^{125} \mathrm{I}-\mathrm{MANF}$, radioactivity in the $\mathrm{SN}$ was at background levels (Fig. 6b). Excesses of unlabeled MANF did not change the result indicating that ${ }^{125} \mathrm{I}-\mathrm{MANF}$ was not transported to the substantia nigra (Fig. $6 b)$. However, ${ }^{125} \mathrm{I}-\mathrm{GDNF}$ was retrogradely transported to the substantia nigra and the transportation was partly inhibited in the presence of 100-400 times molar excess of unlabeled GDNF, as reported previously (Tomac et al., 1995b). When radioactivity was measured from the frontal cortical area, there was five times more radioactivity after ${ }^{125} \mathrm{I}$-MANF injection compared with the radioactivity after ${ }^{125} \mathrm{I}-\mathrm{GDNF}$ injection (Fig. $6 c$ ). Transport of ${ }^{125} \mathrm{I}-\mathrm{MANF}$ to the frontal cortical area was partly inhibited by excess unlabeled MANF (Fig. 6c). The transport of ${ }^{125} \mathrm{I}$-GDNF to the frontal cortical area was not affected markedly by unlabeled GDNF. Thus, MANF transport is clearly different from that of GDNF. MANF was transported to the frontal cortex but not to the SN, whereas GDNF was transported to the $\mathrm{SN}$ after intrastriatal injection.
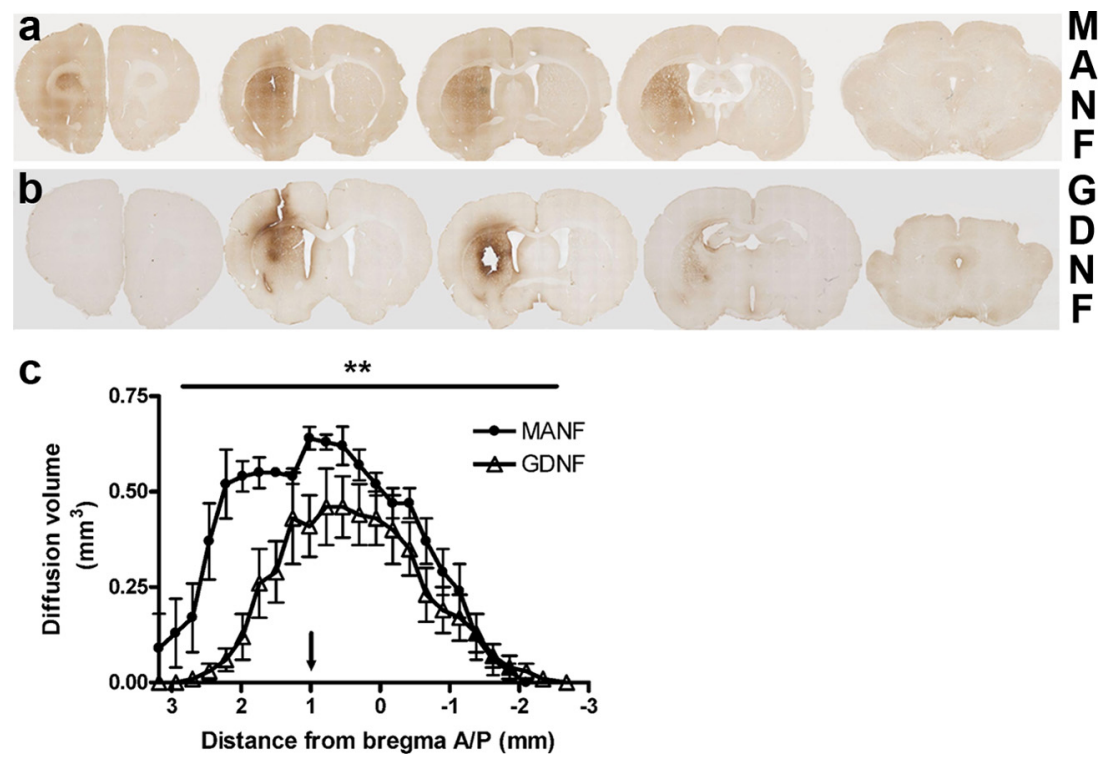

Figure 5. Distribution of MANF and GDNF after a single striatal injection. Rats were administered either MANF (10 $\mu \mathrm{g})$ or GDNF $(10 \mu \mathrm{g})$ unilaterally in the striatum. Representative immunohistochemical staining for MANF $(\boldsymbol{a})$ and GNDF $(\boldsymbol{b})$ in a coronal section through the brain $24 \mathrm{~h}$ after an injection of the neurotrophic factor. $c$, The diffusion profile of MANF also differs from the one of GDNF with statistical significance (the arrow in c points out the site for protein injection in relation to bregma). Means \pm SEM are shown; $n=6$ in both groups. Statistical significance in $c$ was estimated with repeated-measures one-way ANOVA followed by TukeyKramer's post hoc test. ${ }^{* *} p<0.01$.

\section{Discussion}

MANF and CDNF proteins form a novel family of evolutionarily conserved neurotrophic factors (Lindholm et al., 2007, 2008; Palgi et al., 2009). The vertebrates have both MANF and CDNF encoding genes, whereas a single MANF/CDNF homolog is present in the invertebrates (Lindholm et al., 2008). MANF and CDNF are structurally related to each other and resemble none of the known neurotrophic factors (Parkash et al., 2009). Taking into account the structural similarity between CDNF and MANF, we wanted to study whether also recombinant human MANF was able to recover the neural balance controlling movements in rats with unilateral 6-OHDA-induced lesion of the midbrain dopamine neurons.

We used a partial lesion model of dopaminergic nigrostriatal pathway in which 6-OHDA is injected in the striatum (Cadet and Zhu, 1992; Sauer and Oertel, 1994; Lindholm et al., 2007). This model is characterized by a progressive axonal degeneration of the midbrain DA neurons (Sauer and Oertel, 1994; Przedborski et al., 1995). Furthermore, this model gives the opportunity to investigate the effect of treatments not only on protection of DA neurons during the acute phase of cell death but also on regeneration and recovery during the chronic phase of protracted degeneration (Lee et al., 1996; Björklund et al., 1997). The partial lesion model may also mimic the slow neurodegenerative process, which progresses over many years in the brain of parkinsonian patients. In this model, GDNF has been shown to protect nigrostriatal dopaminergic neurons when delivered either to the substantia nigra (Kearns and Gash, 1995; Winkler et al., 1996; Kearns et al., 1997) or to the striatum (Shults et al., 1996; Kirik et al., 2000). GDNF has a lesion site-dependent action because the protective effect is seen only when both the GDNF and the toxin are injected in the same location (Kirik et al., 2000).

In our hands, intrastriatal injection of GDNF $(10 \mu \mathrm{g}) 6 \mathrm{~h}$ before injection of 6-OHDA in the same location showed similar neuroprotective effects as reported previously (Kearns et al., 1997; Kirik et al., 2000; Lindholm et al., 2007). MANF (10 $\mu \mathrm{g})$ reduced the amphetamine-induced ipsilateral rotations even more effectively than GDNF (40 vs 152 turns/120 min in the MANF-treated and GDNF-treated groups, respectively) at 4 weeks after the lesion. MANF showed a bell-shaped doseresponse with the most potent effect at the dose of $10 \mu \mathrm{g} / \mathrm{rat}$. Similar dose-response has been reported previously with GDNF (Hou et al., 1996; Shults et al., 1996). According to the morphological analyses, $10 \mu \mathrm{g}$ of MANF protected $\mathrm{TH}$-positive cells in the SN as effectively as GDNF, and it protected THimmunoreactive fibers in the striatum even more effectively than GDNF. Morphological measures did not correlate completely with the behavioral data probably because the partial lesion model of Parkinson's disease was used. Our results suggest that MANF reduces amphetamine-induced turning behavior and protects DA neurons and striatal axons at least as effectively as GDNF.

In the treatment of PD, neurotrophic factors would be used in patients with severely compromised nigrostriatal dopamine nerves. Therefore, we evaluated the effect of MANF in a neurorestoration model of PD in which MANF $(10 \mu \mathrm{g})$ was injected 4 weeks after a large dose (20 $\mu \mathrm{g} / \mathrm{rat})$ of 6-OHDA in the same site in striatum. Similar to CDNF (Lindholm et al., 2007), also MANF was able to reduce amphetamine-induced turning behavior during the 8 week observation period demonstrating a functional recovery of the dopaminergic and/or other neural circuits that control movements. Different from the results of neuroprotection studies (see above), there was a rather small increase in the number of TH-positive nerve cells in the SN of rats treated with MANF compared with that of vehicle-treated rats. This apparent discrepancy may be attributable to the presence of less severe lesions induced by a small dose of 6-OHDA $(8 \mu \mathrm{g})$ in the neuroprotection paradigm compared with the dose of 6-OHDA (20 $\mu \mathrm{g})$ used in the neurorestoration paradigm. Moreover, in the latter case, the lesion was almost fully developed before MANF was administered, whereas in the neuroprotection study, the tro- 
a
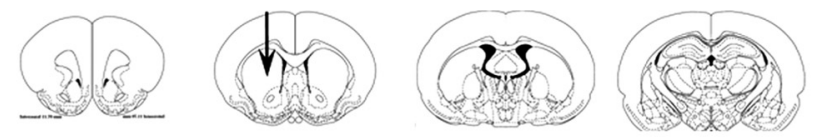

GDNF :

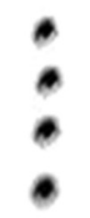

.
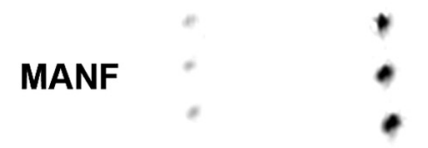

A/P 2.7

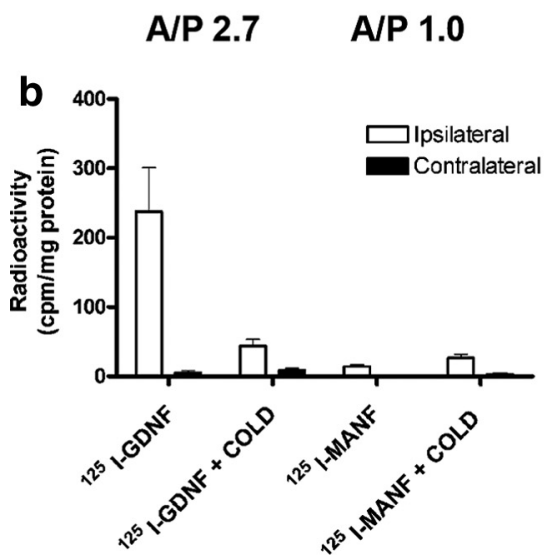

A/P -0.8

A/P -3.3

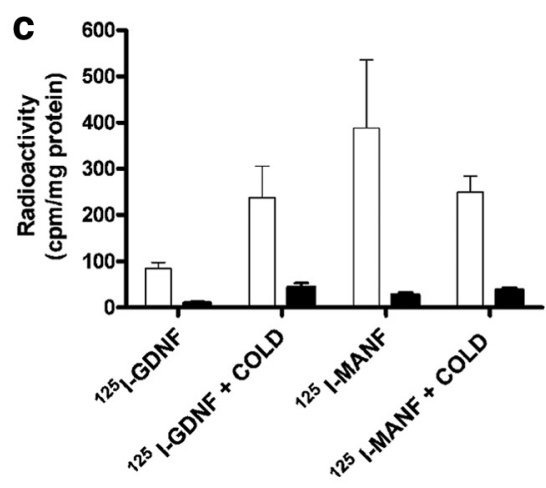

Figure 6. Distribution of ${ }^{125}$ I-GDNF and ${ }^{125}$ I-MANF after intrastriatal injection. $\boldsymbol{a}$, Photomicrograph of the autoradiographic film. Film shows differences in transportation between MANF and GDNF. After intrastriatal injections of ${ }^{125}$ I-MANF and ${ }^{125}$-GDNF, a strong labeling was seen in the injection site (striatum) in sections processed from both two trophic factor-injected brains. ${ }^{125}$ I-MANF is transported to the cortical brain area, but not to the SN. After ${ }^{125}$ I-GDNF injection, strong signal was detected in the SN. Radioactive signal was detected also in the cortex after injection of ${ }^{125} \mathrm{I}$-GDNF. Brain slice figures modified from the rat brain atlas of Paxinos and Watson (1997). A/P 2.70 corresponds to cortex (olfactory bulb), A/P 1.00 corresponds to striatum (injection site), $A / P-0.8$ corresponds to dorsal striatum, A/P -3.30 corresponds to hippocampus, and A/P -5.80 corresponds to substantia nigra. $\boldsymbol{b}, \boldsymbol{c}$, Six microliters of ${ }^{125}$-labeled neurotrophic factor was injected into the left striatum with PBS or (in a competitive manner) with at least 100 -fold excess of either unlabeled MANF or GDNF. Rats were perfused $24 \mathrm{~h}$ later and brain samples were immediately performed for gamma counting. $\boldsymbol{b}$, Radioactivity in the substantia nigra. $\boldsymbol{c}$, Radioactivity in frontal cortical area. The results are expressed as mean $\pm \mathrm{SEM} ; n=8$ in MANF group, $n=10$ in GDNF group.

phic factor was administered as a pretreatment and the follow-up was only up to 4 weeks. In any case, only those dopaminergic nerves not fully destroyed may recover after treatment with neurotrophic factor.

Since the distribution volume seems to be important for the efficacy of neurotrophic factors (Hamilton et al., 2001; Salvatore et al., 2006), we also studied local diffusion of MANF and compared it with GDNF after intrastriatal injection. The volume of distribution on MANF was significantly larger than that of GDNF. This may be of paramount importance for a possible clinical use of MANF because growth factors delivered to human brain have to diffuse significant distances. Indeed, the low benefit of GDNF in recent clinical trials of Parkinson's disease may result from limited tissue distribution (Salvatore et al., 2006). Also, other neurotrophic factors show similar kinds of differences; BDNF produces smaller immunostaining volume than NGF, and NRTN produces smaller immunostaining volume than GDNF in the striatum (Anderson et al., 1995; Hamilton et al., 2001). Different diffusion volumes for various neurotrophic factors may

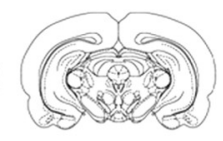

$\cdot$

reflect their ability to interact with tissue components. Indeed, GDNF with a pI of 9.5 has high affinity to heparan sulfates in the ECM that limits the volume of its distribution (Hamilton et al., 2001), whereas MANF has a pI of 7.8 and likely does not bind heparan sulfates in the ECM. Because MANF diffuses readily in the striatum in rats, it may do the same in human brain and be beneficial for the treatment of parkinsonian patients.

We used autoradiographic and gammacounting detection to compare the transportation profiles of intrastriatally injected ${ }^{125} \mathrm{I}-\mathrm{MANF}$ and ${ }^{125} \mathrm{I}-\mathrm{GDNF}$. ${ }^{125}$ I-GDNF was retrogradely transported to the $\mathrm{SN}$ as reported previously by several groups (Tomac et al., 1995b; Leitner et al., 1999). Thus, the method we used was appropriate. Surprisingly, intrastriatally injected ${ }^{125} \mathrm{I}-\mathrm{MANF}$ was not transported to the SN but instead to cortical areas. Thus, the transportation profile of MANF resembles that of NGF after striatal injection (DiStefano et al., 1992; Mufson et al., 1994, 1999). There is a dense glutamatergic input from the cortex to the striatum. Endogenous MANF has also been shown to be expressed in cortex and in striatum (Lindholm et al., 2008). Therefore, we speculate that MANF is retrogradely transported via glutamatergic projection neurons to the cortex. If this holds true, these neurons express receptors for MANF. Most likely, the transportation of MANF requires binding to specific receptors, their internalization, and then their eventual transportation. Retrograde transport of GDNF and NRTN in vivo has been suggested to follow binding to specific receptors (Tomac et al., 1995b; Leitner et al., 1999; Laurikainen et al., 2000). Little information is available about the mechanisms of retrograde signaling used by GDNF family ligands. By analogy with the neurotrophins (Ginty and Segal, 2002), the GDNF family ligands would be expected to bind to specific receptors and to be internalized by distal axons and transported to the cell bodies. Since MANF and CDNF are structurally unrelated to previously identified neurotrophic factors (Parkash et al., 2009), they are likely to activate different signaling mechanisms than those reported for GDNF and BDNF.

The transportation profile of MANF may reflect a mechanism of neurorestorative action that is different from that of GDNF. It can be hypothesized that the functional recovery of the lesioned brain is attributable to indirect effects of MANF on other neural circuits controlling movement and/or controlling dopaminergic activity of the nigrostriatal tract. MANF may modify glutamatergic activity and produces neuroprotection similar to that by glutamate receptor antagonists (Turski et al., 1991; Nicoletti et al., 1996; Sonsalla et al., 1998). Also indirect protective effect on dopaminergic cells via GABAergic neurons is possible. MANF has been shown to increase GABAergic activity regulating DAer- 
gic neuron firing in tissue slices (Petrova et al., 2004) and in dissociated cells in culture (Zhou et al., 2006). We cannot, however, rule out the possibility that minor amounts of MANF not visualized in our transportation experiments can diffuse from striatum to substantia nigra and bind to the receptors on DA neuron cell somas. Furthermore, MANF may have a dual neuroprotective effect by direct effect on dopaminergic nerves, as indicated by in vitro data (Petrova et al., 2003) and through an indirect action through glutamatergic and GABAergic nerves.

At cellular level, MANF may have a dual mechanism of action. The effect of MANF may be related to the inhibition of ER stressinduced cell death. N-terminal domain of CDNF and MANF is a saposin-like lipid-binding domain, which suggests that MANF and CDNF may bind lipids or membranes (Parkash et al., 2009). Structural data on MANF and CDNF indicate that the neurotrophic activity may reside in their $\mathrm{N}$-terminal domains and ER stress response in their C-terminal domains. Although 6-OHDA induces its neurotoxic effect mainly by inhibiting mitochondrial complex I (Sachs et al., 1975) and production of reactive oxygen species, it also induces ER stress (Chen et al., 2004). MANF is a soluble protein that resides in endoplasmic reticulum and Golgi apparatus (Mizobuchi et al., 2007; Apostolou et al., 2008). Recently, MANF expression was shown to be upregulated in brain ischemia in rats, and it was shown to inhibit ER stress-induced cell death in HeLa cells in vitro (Apostolou et al., 2008). Thus, at least part of the neuroprotective effect of MANF against 6-OHDA-induced neurotoxicity may be attributable to inhibition of ER stress.

MANF has significant protective properties for DA neurons. The precise mechanisms how MANF exerts neuroprotective and neurorestorative actions remain to be determined. However, this study shows that MANF elicits its neuroprotective and neurorestorative effects on DA neurons by a different mechanism than GDNF. Together, protection of striatal dopaminergic cells may be achieved with various neurotrophic factors acting on different neural circuits.

\section{References}

Anderson KD, Alderson RF, Altar CA, DiStefano PS, Corcoran TL, Lindsay RM, Wiegand SJ (1995) Differential distribution of exogenous BDNF, NGF, and NT-3 in the brain corresponds to the relative abundance and distribution of high-affinity and low-affinity neurotrophin receptors. J Comp Neurol 357:296-317.

Apostolou A, Shen Y, Liang Y, Luo J, Fang S (2008) Armet, a UPRupregulated protein, inhibits cell proliferation and ER stress-induced cell death. Exp Cell Res 314:2454-2467.

Bespalov MM, Saarma M (2007) GDNF family receptor complexes are emerging drug targets. Trends Pharmacol Sci 28:68-74.

Björklund A, Rosenblad C, Winkler C, Kirik D (1997) Studies on neuroprotective and regenerative effects of GDNF in a partial lesion model of Parkinson's disease. Neurobiol Dis 4:186-200.

Cadet JL, Zhu SM (1992) The intrastriatal 6-hydroxydopamine model of hemiparkinsonism: quantitative receptor autoradiographic evidence of correlation between circling behavior and presynaptic as well as postsynaptic nigrostriatal markers in the rat. Brain Res 595:316-326.

Chen G, Bower KA, Ma C, Fang S, Thiele CJ, Luo J (2004) Glycogen synthase kinase 3beta (GSK3beta) mediates 6-hydroxydopamine-induced neuronal death. FASEB J 18:1162-1164.

Dauer W, Przedborski S (2003) Parkinson's disease: mechanisms and models. Neuron 39:889-909.

Di Stefano A, Sozio P, Cerasa LS (2008) Antiparkinson prodrugs. Molecules 13:46-68.

DiStefano PS, Friedman B, Radziejewski C, Alexander C, Boland P, Schick CM, Lindsay RM, Wiegand SJ (1992) The neurotrophins BDNF, NT-3, and NGF display distinct patterns of retrograde axonal transport in peripheral and central neurons. Neuron 8:983-993.

Gash DM, Zhang Z, Ovadia A, Cass WA, Yi A, Simmerman L, Russell D,
Martin D, Lapchak PA, Collins F, Hoffer BJ, Gerhardt GA (1996) Functional recovery in parkinsonian monkeys treated with GDNF. Nature 380:252-255.

Gill SS, Patel NK, Hotton GR, O’Sullivan K, McCarter R, Bunnage M, Brooks DJ, Svendsen CN, Heywood P (2003) Direct brain infusion of glial cell line-derived neurotrophic factor in Parkinson disease. Nat Med 9:589-595.

Ginty DD, Segal RA (2002) Retrograde neurotrophin signaling: Trk-ing along the axon. Curr Opin Neurobiol 12:268-274.

Hamilton JF, Morrison PF, Chen MY, Harvey-White J, Pernaute RS, Phillips H, Oldfield E, Bankiewicz KS (2001) Heparin coinfusion during convection-enhanced delivery (CED) increases the distribution of the glial-derived neurotrophic factor (GDNF) ligand family in rat striatum and enhances the pharmacological activity of neurturin. Exp Neurol 168:155-161.

Hoffer BJ, Hoffman A, Bowenkamp K, Huettl P, Hudson J, Martin D, Lin LF, Gerhardt GA (1994) Glial cell line-derived neurotrophic factor reverses toxin-induced injury to midbrain dopaminergic neurons in vivo. Neurosci Lett 182:107-111.

Horger BA, Nishimura MC, Armanini MP, Wang LC, Poulsen KT, Rosenblad C, Kirik D, Moffat B, Simmons L, Johnson E Jr, Milbrandt J, Rosenthal A, Björklund A, Vandlen RA, Hynes MA, Phillips HS (1998) Neurturin exerts potent actions on survival and function of midbrain dopaminergic neurons. J Neurosci 18:4929-4937.

Hou JG, Lin LF, Mytilineou C (1996) Glial cell line-derived neurotrophic factor exerts neurotrophic effects on dopaminergic neurons in vitro and promotes their survival and regrowth after damage by 1-methyl-4phenylpyridinium. J Neurochem 66:74-82.

Kearns CM, Gash DM (1995) GDNF protects nigral dopamine neurons against 6-hydroxydopamine in vivo. Brain Res 672:104-111.

Kearns CM, Cass WA, Smoot K, Kryscio R, Gash DM (1997) GDNF protection against 6-OHDA: time dependence and requirement for protein synthesis. J Neurosci 17:7111-7118.

Kirik D, Rosenblad C, Björklund A (2000) Preservation of a functional nigrostriatal dopamine pathway by GDNF in the intrastriatal 6-OHDA lesion model depends on the site of administration of the trophic factor. Eur J Neurosci 12:3871-3882.

Kotzbauer PT, Lampe PA, Heuckeroth RO, Golden JP, Creedon DJ, Johnson EM Jr, Milbrandt J (1996) Neurturin, a relative of glial-cell-line-derived neurotrophic factor. Nature 384:467-470.

Lang AE, Gill S, Patel NK, Lozano A, Nutt JG, Penn R, Brooks DJ, Hotton G, Moro E, Heywood P, Brodsky MA, Burchiel K, Kelly P, Dalvi A, Scott B, Stacy M, Turner D, Wooten VG, Elias WJ, Laws ER, et al. (2006) Randomized controlled trial of intraputamenal glial cell line-derived neurotrophic factor infusion in Parkinson disease. Ann Neurol 59:459-466.

Lapchak PA, Jiao S, Collins F, Miller PJ (1997) Glial cell line-derived neurotrophic factor: distribution and pharmacology in the rat following a bolus intraventricular injection. Brain Res 747:92-102.

Laurikainen A, Hiltunen JO, Vanhatalo S, Klinge E, Saarma M (2000) Glial cell line-derived neurotrophic factor is expressed in penis of adult rat and retrogradely transported in penile parasympathetic and sensory nerves. Cell Tissue Res 302:321-329.

Lee CS, Sauer H, Björklund A (1996) Dopaminergic neuronal degeneration and motor impairments following axon terminal lesion by instrastriatal 6-hydroxydopamine in the rat. Neuroscience 72:641-653.

Leitner ML, Molliver DC, Osborne PA, Vejsada R, Golden JP, Lampe PA, Kato AC, Milbrandt J, Johnson EM Jr (1999) Analysis of the retrograde transport of glial cell line-derived neurotrophic factor (GDNF), neurturin, and persephin suggests that in vivo signaling for the GDNF family is GFRalpha coreceptor-specific. J Neurosci 19:9322-9331.

Lindholm P, Voutilainen MH, Laurén J, Peränen J, Leppänen VM, Andressoo JO, Lindahl M, Janhunen S, Kalkkinen N, Timmusk T, Tuominen RK, Saarma M (2007) Novel neurotrophic factor CDNF protects and rescues midbrain dopamine neurons in vivo. Nature 448:73-77.

Lindholm P, Peränen J, Andressoo JO, Kalkkinen N, Kokaia Z, Lindvall O, Timmusk T, Saarma M (2008) MANF is widely expressed in mammalian tissues and differently regulated after ischemic and epileptic insults in rodent brain. Mol Cell Neurosci 39:356-371.

Marks WJ Jr, Ostrem JL, Verhagen L, Starr PA, Larson PS, Bakay RA, Taylor R, Cahn-Weiner DA, Stoessl AJ, Olanow CW, Bartus RT (2008) Safety and tolerability of intraputaminal delivery of CERE-120 (adeno- 
associated virus serotype 2-neurturin) to patients with idiopathic Parkinson's disease: an open-label, phase I trial. Lancet Neurol 7:400-408.

Mizobuchi N, Hoseki J, Kubota H, Toyokuni S, Nozaki J, Naitoh M, Koizumi A, Nagata K (2007) ARMET is a soluble ER protein induced by the unfolded protein response via ERSE-II element. Cell Struct Funct 32:41-50.

Mufson EJ, Kroin JS, Sobreviela T, Burke MA, Kordower JH, Penn RD, Miller JA (1994) Intrastriatal infusions of brain-derived neurotrophic factor: retrograde transport and colocalization with dopamine containing substantia nigra neurons in rat. Exp Neurol 129:15-26.

Mufson EJ, Kroin JS, Sendera TJ, Sobreviela T (1999) Distribution and retrograde transport of trophic factors in the central nervous system: functional implications for the treatment of neurodegenerative diseases. Prog Neurobiol 57:451-484.

Nicoletti F, Bruno V, Copani A, Casabona G, Knöpfel T (1996) Metabotropic glutamate receptors: a new target for the therapy of neurodegenerative disorders? Trends Neurosci 19:267-271.

Nutt JG, Burchiel KJ, Comella CL, Jankovic J, Lang AE, Laws ER Jr, Lozano AM, Penn RD, Simpson RK Jr, Stacy M, Wooten GF; ICV GDNF Study Group. Implanted intracerebroventricular. Glial cell line-derived neurotrophic factor (2003) Randomized, double-blind trial of glial cell linederived neurotrophic factor (GDNF) in PD. Neurology 60:69-73.

Oiwa Y, Yoshimura R, Nakai K, Itakura T (2002) Dopaminergic neuroprotection and regeneration by neurturin assessed by using behavioral, biochemical and histochemical measurements in a model of progressive Parkinson's disease. Brain Res 947:271-283.

Palgi M, Lindström R, Peränen J, Piepponen TP, Saarma M, Heino TI (2009) Evidence that DmMANF is an invertebrate neurotrophic factor supporting dopaminergic neurons. Proc Natl Acad Sci U S A 106:2429-2434.

Parkash V, Lindholm P, Peränen J, Kalkkinen N, Oksanen E, Saarma M, Leppanen VM, Goldman A (2009) The structure of the conserved neurotrophic factors MANF and CDNF explains why they are bifunctional. Protein Eng Des Sel 22:233-241.

Paxinos G, Watson C (1997) The rat brain in stereotaxic coordinates. San Diego: Academic.

Peränen J, Rikkonen M, Hyvönen M, Kääriäinen L (1996) T7 vectors with modified T7lac promoter for expression of proteins in Escherichia coli. Anal Biochem 236:371-373.

Petrova P, Raibekas A, Pevsner J, Vigo N, Anafi M, Moore MK, Peaire AE, Shridhar V, Smith DI, Kelly J, Durocher Y, Commissiong JW (2003) MANF: a new mesencephalic, astrocyte-derived neurotrophic factor with selectivity for dopaminergic neurons. J Mol Neurosci 20:173-188.

Petrova PS, Raibekas A, Pevsner J, Vigo N, Anafi M, Moore MK, Peaire A, Shridhar V, Smith DI, Kelly J, Durocher Y, Commissiong JW (2004) Discovering novel phenotype-selective neurotrophic factors to treat neurodegenerative diseases. Prog Brain Res 146:168-183.

Przedborski S, Levivier M, Jiang H, Ferreira M, Jackson-Lewis V, Donaldson D, Togasaki DM (1995) Dose-dependent lesions of the dopaminergic nigrostriatal pathway induced by intrastriatal injection of 6-hydroxydopamine. Neuroscience 67:631-647.

Rosenblad C, Kirik D, Devaux B, Moffat B, Phillips HS, Björklund A (1999)
Protection and regeneration of nigral dopaminergic neurons by neurturin or GDNF in a partial lesion model of Parkinson's disease after administration into the striatum or the lateral ventricle. Eur J Neurosci 11:1554-1566.

Sachs C, Jonsson G, Heikkila R, Cohen G (1975) Control of the neurotoxicity of 6-hydroxydopamine by intraneuronal noradrenaline in rat iris. Acta Physiol Scand 93:345-351.

Salvatore MF, Ai Y, Fischer B, Zhang AM, Grondin RC, Zhang Z, Gerhardt GA, Gash DM (2006) Point source concentration of GDNF may explain failure of phase II clinical trial. Exp Neurol 202:497-505.

Sauer H, Oertel WH (1994) Progressive degeneration of nigrostriatal dopamine neurons following intrastriatal terminal lesions with 6-hydroxydopamine: a combined retrograde tracing and immunocytochemical study in the rat. Neuroscience 59:401-415.

Shults CW, Kimber T, Martin D (1996) Intrastriatal injection of GDNF attenuates the effects of 6-hydroxydopamine. Neuroreport 7:627-631.

Slevin JT, Gerhardt GA, Smith CD, Gash DM, Kryscio R, Young B (2005) Improvement of bilateral motor functions in patients with Parkinson disease through the unilateral intraputaminal infusion of glial cell linederived neurotrophic factor. J Neurosurg 102:216-222.

Sonsalla PK, Albers DS, Zeevalk GD (1998) Role of glutamate in neurodegeneration of dopamine neurons in several animal models of parkinsonism. Amino Acids 14:69-74.

Tomac A, Lindqvist E, Lin LF, Ogren SO, Young D, Hoffer BJ, Olson L (1995a) Protection and repair of the nigrostriatal dopaminergic system by GDNF in vivo. Nature 373:335-339.

Tomac A, Widenfalk J, Lin LF, Kohno T, Ebendal T, Hoffer BJ, Olson L (1995b) Retrograde axonal transport of glial cell line-derived neurotrophic factor in the adult nigrostriatal system suggests a trophic role in the adult. Proc Natl Acad Sci U S A 92:8274-8278.

Turski L, Bressler K, Rettig KJ, Löschmann PA, Wachtel H (1991) Protection of substantia nigra from MPP + neurotoxicity by $N$-methyl-Daspartate antagonists. Nature 349:414-418.

Ungerstedt U, Arbuthnott GW (1970) Quantitative recording of rotational behavior in rats after 6-hydroxy-dopamine lesions of the nigrostriatal dopamine system. Brain Res 24:485-493.

West MJ, Slomianka L, Gundersen HJ (1991) Unbiased stereological estimation of the total number of neurons in thesubdivisions of the rat hippocampus using the optical fractionator. Anat Rec 231:482-497.

Winkler C, Sauer H, Lee CS, Björklund A (1996) Short-term GDNF treatment provides long-term rescue of lesioned nigral dopaminergic neurons in a rat model of Parkinson's disease. J Neurosci 16:7206-7215.

Zhang Z, Miyoshi Y, Lapchak PA, Collins F, Hilt D, Lebel C, Kryscio R, Gash DM (1997) Dose response to intraventricular glial cell line-derived neurotrophic factor administration in parkinsonian monkeys. J Pharmacol Exp Ther 282:1396-1401.

Zhou C, Xiao C, Commissiong JW, Krnjević K, Ye JH (2006) Mesencephalic astrocyte-derived neurotrophic factor enhances nigral gammaaminobutyric acid release. Neuroreport 17:293-297. 